ARTICLE

\title{
Optical control of insulin release using a photoswitchable sulfonylurea
}

Johannes Broichhagen ${ }^{1}$, Matthias Schönberger ${ }^{1}$, Simon C. Cork ${ }^{2}$, James A. Frank ${ }^{1}$, Piero Marchetti ${ }^{3}$, Marco Bugliani ${ }^{3}$, A.M. James Shapiro ${ }^{4}$, Stefan Trapp ${ }^{2}$, Guy A. Rutter ${ }^{5}$, David J. Hodson ${ }^{5}$ \& Dirk Trauner ${ }^{1}$

Sulfonylureas are widely prescribed for the treatment of type 2 diabetes mellitus (T2DM). Through their actions on ATP-sensitive potassium $\left(\mathrm{K}_{\text {ATP }}\right.$ ) channels, sulfonylureas boost insulin release from the pancreatic beta cell mass to restore glucose homeostasis. A limitation of these compounds is the elevated risk of developing hypoglycemia and cardiovascular disease, both potentially fatal complications. Here, we describe the design and development of a photoswitchable sulfonylurea, JB253, which reversibly and repeatedly blocks $\mathrm{K}_{\text {ATP }}$ channel activity following exposure to violet-blue light. Using in situ imaging and hormone assays, we further show that JB253 bestows light sensitivity upon rodent and human pancreatic beta cell function. Thus, JB253 enables the optical control of insulin release and may offer a valuable research tool for the interrogation of $K_{\text {ATP }}$ channel function in health and T2DM.

\footnotetext{
${ }^{1}$ Department of Chemistry, Ludwig-Maximilians-Universität München, and Munich Center for Integrated Protein Science, Butenandtstrasse 5-13, 81377 München, Germany. ${ }^{2}$ Division of Biosciences, Department of Neuroscience, Physiology and Pharmacology, University College London, London WC1E 6BT, UK. ${ }^{3}$ Department of Clinical and Experimental Medicine, Islet Cell Laboratory, University of Pisa, 56126 Pisa, Italy. ${ }^{4}$ Clinical Islet Laboratory and Clinical Islet transplant program, University of Alberta, Edmonton, Alberta T6G 2C8, Canada. ${ }^{5}$ Section of Cell Biology, Department of Medicine, Imperial College London, Imperial Centre for Translational and Experimental Medicine, Hammersmith Hospital, Du Cane Road, London W12 ONN, UK. Correspondence and requests for materials should be addressed to D.J.H. (email: d.hodson@imperial.ac.uk) or to D.T. (email: dirk.trauner@lmu.de).
} 
T ype 2 diabetes mellitus (T2DM) is a global health-care epidemic associated with life-changing sequelae ranging from blindness to cancer ${ }^{1,2}$. This endocrine disease, which currently affects 1 in 12 of the adult population worldwide, involves a disturbance of normal glucose homeostasis due to failure of the pancreatic beta cell mass to adequately compensate for increased peripheral insulin resistance ${ }^{3}$. As such, the rescue of insulin release through the coaxing of beta cell activity remains a therapeutically desirable approach for the long-term restoration of normal glucose levels.

Sulfonylureas, which target ATP-sensitive potassium $\left(\mathrm{K}^{+}\right)$ $\left(\mathrm{K}_{\mathrm{ATP}}\right)$ channels, are a mainstay of diabetes therapy ${ }^{4-6} . \mathrm{K}_{\mathrm{ATP}}$ channels are hetero-octameric structures composed of four regulatory sulfonylurea receptor subunits (SUR1) and four Kir6.2 subunits, the latter forming a central ion pore that permits $\mathrm{K}^{+}$ efflux $^{7-9}$. By binding to SUR1, sulfonylureas block the Kir6.2 inward rectifier, leading to cell depolarization and opening of voltage-dependent $\mathrm{Ca}^{2+}$ channels $(\mathrm{VDCC})^{10,11}$. The ensuing $\mathrm{Ca}^{2+}$ influx ${ }^{12,13}$, along with $\mathrm{K}_{\mathrm{ATP}}$ channel-independent signals ${ }^{14}$, drives various downstream processes that ultimately converge on the exocytosis of insulin ${ }^{15}$. Elevated circulating insulin can then act on target tissues to improve glucose uptake, hepatic glycogenesis and fatty acid synthesis ${ }^{16}$ (Supplementary Fig. 1).

While sulfonylureas are widely prescribed because of their effectiveness and relative inexpensiveness, they have a range of off-target effects that limits their therapeutic use. For example, sulfonylureas can provoke prolonged episodes of low blood glucose due to hyperinsulinemia ${ }^{17}$, elevate cardiovascular disease risk $^{18}$ and induce weight gain ${ }^{19}$. Conversely, there is a lack of tools for the precise functional dissection of $\mathrm{K}_{\mathrm{ATP}}$ channels located not only in the pancreas, but also in the brain ${ }^{20,21}$, heart ${ }^{22}$ and vascular smooth muscle ${ }^{23}$. With this in mind, we set out to combine the glucose-lowering attributes of sulfonylureas with the exquisite spatiotemporal control conferred by possession of photoresponsive elements ${ }^{24,25}$.

Here, we showcase JB253, a 'fourth-generation' sulfonylurea based on glimepiride that bears an azobenzene photoswitch, endowing $\mathrm{K}_{\mathrm{ATP}}$ channels with remarkable photocontrollable properties (Fig. 1a). We demonstrate that JB253 offers sensitive, reversible and repeated manipulation of $\mathrm{K}_{\mathrm{ATP}}$ channel state and beta cell activity with visible light, yielding optical control over insulin release. Thus, JB253 may allow the selective targeting of $\mathrm{K}_{\mathrm{ATP}}$ channels in the pancreas and elsewhere.

\section{Results}

Design and synthesis of JB253. Distinct substitution patterns are found within different classes of arylsulfonylurea drugs: while there may be a variety of moieties on the aryl-ring, ranging from a simple methyl group in tolbutamide to more complex structures such as a linked pyrrolidinone in glimepiride (Fig. 1b), the terminal nitrogen in sulfonylureas is usually substituted with an aliphatic group. We reasoned that, to generate a photoswitchable analogue, the aromatic core of the sulfonylurea drugs could be extended to an azobenzene. Furthermore, we aimed for a cyclohexyl substituent on the urea moiety that mimics the corresponding substituent on glimepiride. Using a simple threestep procedure commencing with sulfanilamide, $N, N$-diethylaniline and cyclohexyl isocyanate, JB253 could be synthesized rapidly and inexpensively in large quantities via the sulfonamide-azobenzene (E)-4-((4-(diethylamino)phenyl)-diazenyl)benzenesulfonamide (Fig. 1c; Supplementary Figs 2-4). Initial photochromic characteristics of JB253 were measured using a ultraviolet/visible (Vis) spectrophotometer equipped with a monochromator, affording a single broad band as expected for a push-pull-azobenzene-system ( $\left.\lambda_{\max }=472 \mathrm{~nm}\right)$ (Fig. 1d).
Azobenzenes are known to be photoconverted between their cis- and trans-state by excitation with different wavelengths of light, or alternatively by illumination and dark-relaxation. Indeed, JB253 was readily converted to its cis-state by applying wavelengths ranging from $\lambda=400$ to $500 \mathrm{~nm}$ (peak $\lambda=472 \mathrm{~nm}$ ), while thermal relaxation to its trans-state occurred rapidly in the dark. X-ray diffractometry revealed a high degree of structural similarity between trans-JB253 and glimepiride crystals ${ }^{26}$ (Fig. 1e) (see Supplementary Table 1). Whereas glimepiride in solution rotates freely around its ethylene carbon chain to adopt various possible binding conformations, JB253 is rigid unless illuminated and so can only adopt two conformations depending on isomeric state (that is, trans- or cis-).

Attaching lipophilic azobenzene units normally renders molecules poorly soluble in water and aqueous buffers, an obvious drawback for their use in biological systems. JB253, however, demonstrates excellent water solubility $(\geq 0.1 \mathrm{mM})$ when diluted from a $50 \mathrm{mM}$ stock solution in dimethyl sulfoxide (DMSO), presumably due to its acidity $\left(p K_{a}\right.$ (trans-JB253) $=4.76$; see Supplementary Fig. 5). These features were a promising entry point for our subsequent studies using mammalian tissue.

JB253-binding studies. To determine the binding affinity of JB253 to SUR1 relative to a known sulfonylurea (that is, glimepiride), $[3 \mathrm{H}]$-glibenclamide displacement assays were performed. JB253 bound SUR1 with a 1,000-fold lower affinity compared with glimepiride, and this was unaffected by illumination (halfmaximal inhibitory concentration $\left(\mathrm{IC}_{50}\right)=8.3 \mathrm{nM}$ versus $17.6 \mu \mathrm{M}$ versus $14.8 \mu \mathrm{M}$ for glimepiride versus trans-JB253 versus cisJB253, respectively) (Fig. 2a). However, owing to the potential for rapid thermal dark-relaxation during the wash cycles (see below), we were unable to exclude a role for trans- to cis-isomerization in strengthening JB253 binding affinity. Therefore, to compare the activity profiles of trans-JB253, cis-JB253 and glimepiride using a functionally relevant readout, concentration-response experiments were conducted in mouse islets. The effector concentration for half-maximum response $\left(\mathrm{EC}_{50}\right)$ of cis-JB253 for cytosolic $\mathrm{Ca}^{2+}$ rises was found to be $675 \mathrm{nM}$, similar to that obtained for glimepiride in the same system $\left(\mathrm{EC}_{50}\right.$ glimepiride $\left.=399 \mathrm{nM}\right)$ (Fig. 2b). The concentration-response curve for glimepiride was right-shifted in the presence of a saturating concentration of trans-JB253, demonstrating the presence of competitive agonism even under dark conditions (Fig. 2b).

Since most sulfonlyureas have been reported to bind and activate Exchange Protein directly Activated by cAMP 2A $(\text { Epac2A })^{27}$, an important mediator of insulin secretion ${ }^{28,29}$, the presence of interactions with JB253 was assessed using a Förster resonance energy transfer (FRET)-based approach. To enable this, a full-length Epac2-camps biosensor containing the sulfonylureabinding site was encoded in HEK293t cells ${ }^{29}$. Confirming the existence of sufonylurea-Epac2A interactions, application of either glimepiride (Fig. 2c) or cis-JB253 (Fig. 2d) decreased FRET to a similar extent $\left(\Delta R / R_{\mathrm{o}}=0.052\right.$ versus 0.064 a.u., glimepiride versus JB253, respectively; NS, not significant, Student's $t$-test).

JB253 allows photoswitching of $\mathbf{K}_{\mathrm{ATP}}$ channels. We sought first to investigate whether JB253 could yield optical control over $\mathrm{K}_{\mathrm{ATP}}$ channel activity using a system free from confounding effects of glucose metabolism. To enable this, $\mathrm{K}_{\mathrm{ATP}}$ channels were heterologously expressed in HEK293t cells by transfection with plasmids encoding the Kir6.2 and SUR1 subunits along with green fluorescent protein. Tolbutamide and diazoxide-sensitive inward-rectifying $\mathrm{K}^{+}$currents could be recorded in transfected cells, confirming the functional assembly of $\mathrm{K}_{\mathrm{ATP}}$ channels. In the dark state, JB253 partly reduced $\mathrm{K}^{+}$current amplitude within a 
a

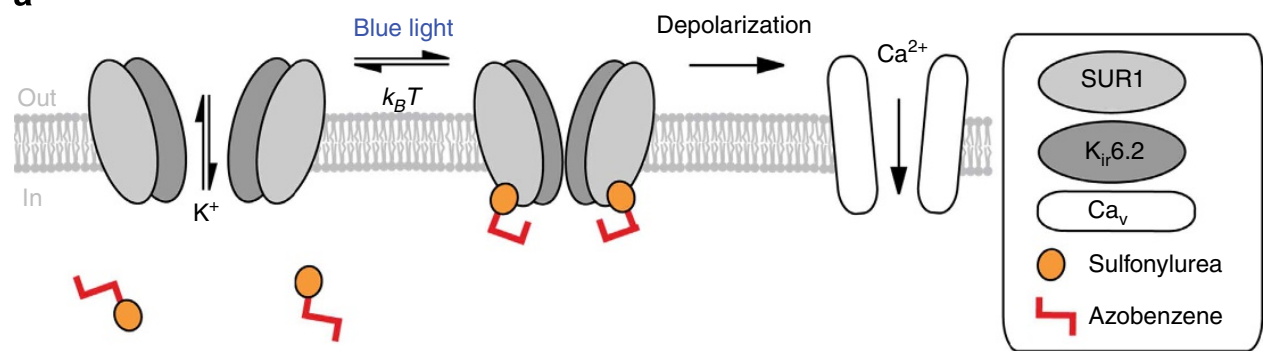

b<smiles>CCCCNC(=O)NS(=O)(=O)c1ccc(C)cc1</smiles>

Tolbutamide<smiles>CCC1=C(C)CN(C(=O)NCCc2ccc(SNC(=O)NC3CCC(C)CC3)cc2)C1=O</smiles>

C<smiles>Nc1ccc(S(N)(=O)=O)cc1</smiles>
Sulfanilamide

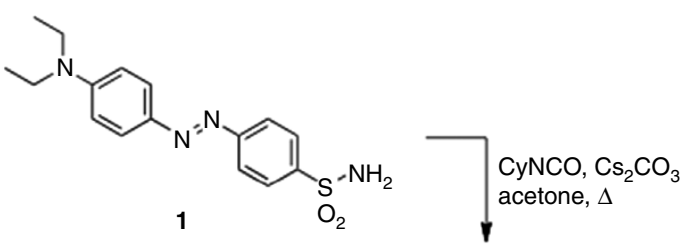<smiles>CCN(CC)c1ccc(/N=N\c2ccc(SNC(=O)NC3CCCCC3)cc2)cc1</smiles><smiles>CCN(CC)c1ccc(N=Nc2ccc(S(=O)(=O)NC(=O)NC3CCCCC3)cc2)cc1</smiles>

cis-JB253

trans-JB253
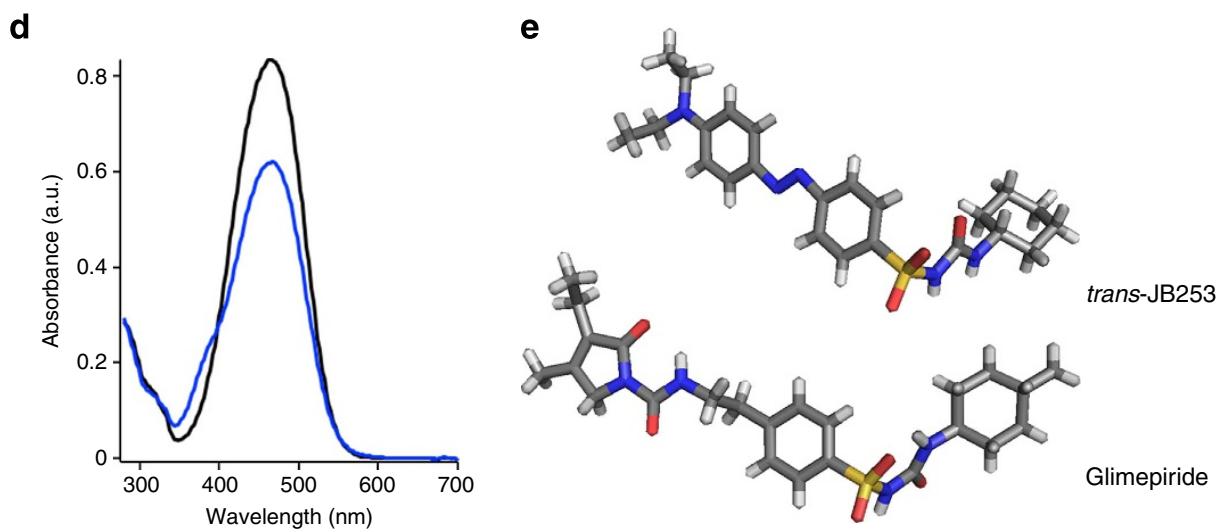

Figure 1 | Photopharmacology of $\mathbf{K}_{\mathbf{A T P}}$ channels: design, synthesis and characteristics of JB253. (a) The logic of a photoswitchable sulfonylurea: upon photoisomerization to the cis-state, JB253 becomes more active, closing the $\mathrm{K}_{\text {ATP }}$ channel. Thermal relaxation makes the compound less active or leads to dissociation, restoring the open form of the channel. Closure of $\mathrm{K}_{\text {ATP }}$ channels leads to depolarization, promoting calcium influx and ultimately insulin release. (b) Chemical structure of tolbutamide and glimepiride, which served as templates for JB253. (c) Synthesis, structure and switching characteristics of JB253. Sulfanilamide undergoes diazotization and is trapped with $\mathrm{N}, \mathrm{N}$-diethylaniline to yield an azobenzene-sulfonamide, which is converted to JB253 by cyclohexyl isocyanate. trans-JB253 can be reversibly switched to cis-JB253 with blue light and relaxes thermally. (d) ultraviolet/Vis spectra of JB253 in the dark (black) and during constant illumination with $460 \mathrm{~nm}$ (blue). (e) Crystal structure of trans-JB253 (CCDC: 1014606) and glimepiride (CSD: TOHBUN01) showing the structural similarity of both sulfonylureas.

few seconds. This was, however, a fraction of that observed during $500 \mu \mathrm{M}$ tolbutamide application (Supplementary Fig. 6a,b). Subsequent illumination of JB253 with wavelengths between 400 and $500 \mathrm{~nm}$ further closed the channel (Fig. 3a), with $\sim 45-72 \%$ block being achieved relative to that recorded using $500 \mu \mathrm{M}$ tolbutamide (Supplementary Table 2). The reversal potential was close to the expected equilibrium potential for $\mathrm{K}^{+}$, and this was unaffected by molecule orientation $(-90.0 \pm 1.8$ versus $-87.8 \pm 1.6 \mathrm{mV}$, dark versus illuminated; not significant) (Supplementary Fig. 6c,d). As such, JB253 possesses the advantageous property of becoming a high-affinity $\mathrm{K}_{\mathrm{ATP}}$ channel blocker upon illumination.

Using a wavelength of $400 \mathrm{~nm}$, heterologously expressed $\mathrm{K}_{\mathrm{ATP}}$ channels could be repeatedly opened and closed in JB253-treated 
a

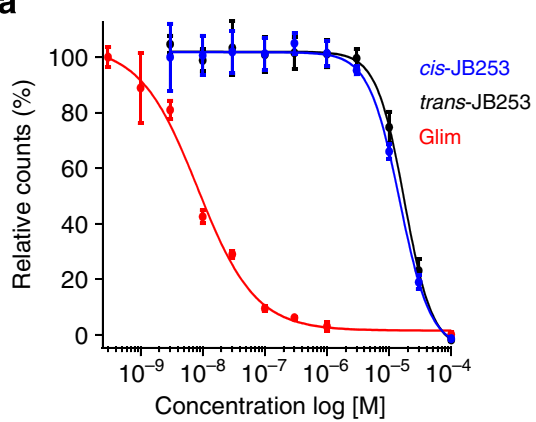

b

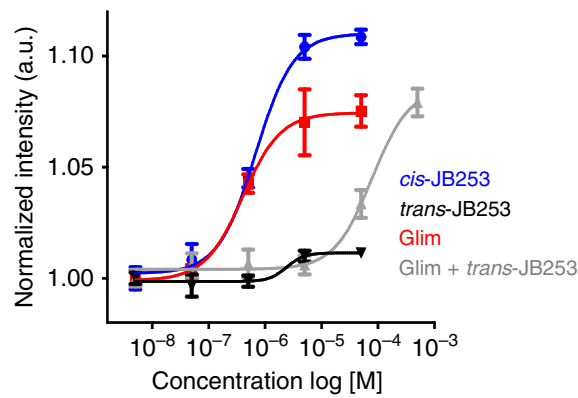

C

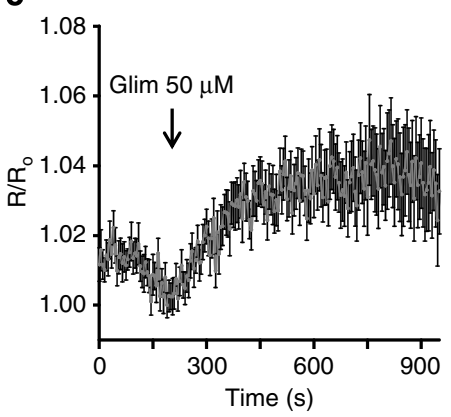

d

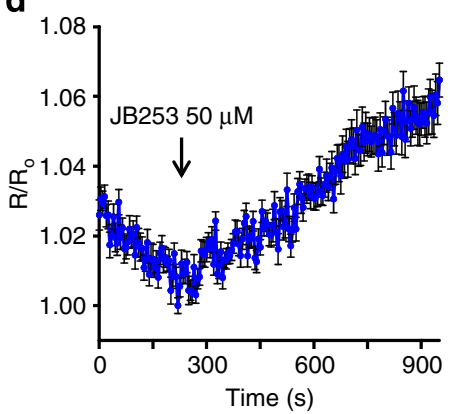

Figure 2 | JB253 binding and concentration-response studies. (a) Binding affinity of glimepiride (Glim) (red, IC $50=8.3 \mathrm{nM}$ ), trans-JB253 (black, $I C_{50}=17.6 \mu \mathrm{M}$ ) and cis-JB253 (blue, $\mathrm{IC}_{50}=14.8 \mu \mathrm{M}$ ) were indirectly determined in SUR1-expressing HEK293t cells using displacement of [3H]glibenclamide (data points fitted using the Hill equation) ( $n=3$ independent repeats). Note that, due to the potential for thermal dark-relaxation during the harvesting and washing steps, effects of photoswitching on JB253 binding affinity could not be excluded. Values represent the mean \pm s.d. (b) cis-JB253 and glimepiride $(\mathrm{Glim})$ possess similar concentration-response curves for the stimulation of $\left[\mathrm{Ca}^{2+}\right]_{\mathrm{i}}$ in mouse islets, while trans-JB253 is largely ineffective. The concentration-response for glimepiride is right-shifted in the presence of a saturating concentration (100 $\mu \mathrm{M}$ ) of trans-JB253 (data points fitted using nonlinear regression) ( $n=3$ recordings). (c) HEK293t cells expressing a full-length Epac2-camps probe respond to glimepiride with decreases in Förster resonance energy transfer (FRET) (represented here as an increase in $R / R_{\mathrm{o}}$ ) ( $n=28$ cells from 4 recordings). (d) As in c, but cis-JB253. Values represent the mean \pm s.e.m. for $(\mathbf{b}-\mathbf{d})$.

preparations without obvious desensitization (difference in $\Delta \mathrm{I}$ $[\mathrm{pA}]$ between first and last switch $=14.9 \pm 7.6 \%$ ) (Fig. 3b; Supplementary Tables 3 and 4). Upon exposure to $400 \mathrm{~nm}$, rapid block was observed $\left(\tau_{\text {on }}=0.4 \mathrm{~s}\right)$ (Fig. $3 \mathrm{c}$ ). When the light source was shut off, thermal relaxation was fast, returning the $\mathrm{K}_{\mathrm{ATP}}$ channel to baseline levels within a couple of seconds $\left(\tau_{\text {off }}=1.5 \mathrm{~s}\right)$ (Fig. 3c; Supplementary Tables 3 and 4). While maximal photoblock of $K_{\mathrm{ATP}}$ channels was observed at $460 \mathrm{~nm}$, significant effects were also obtained with violet light (that is, $405 \mathrm{~nm}$ ), which was more compatible with fluorescence imaging of pancreatic beta cell function (see below). Confirming that JB253 could photoswitch endogenous $\mathrm{K}_{\mathrm{ATP}}$ channels, hyperpolarizing currents were reversibly blocked in MIN6 beta cells following illumination (Supplementary Fig. 7).

Functional interrogation of beta cells within mouse islets. Stimulus-secretion coupling in beta cells relies on the closure of $\mathrm{K}_{\mathrm{ATP}}$ channels, $\mathrm{Ca}^{2}+$ influx through VDCC and release of insulin granules ${ }^{12}$. We therefore attempted to manipulate beta cell activity by optically controlling $\mathrm{K}_{\mathrm{ATP}}$ channels with JB253.

Using functional multicellular $\mathrm{Ca}^{2}+$ imaging to monitor cell activity directly in situ within intact islets ${ }^{30,31}$, increases in cytosolic free $\mathrm{Ca}^{2+}$, assumed largely to emanate from beta cells under the conditions used here ${ }^{32}$, could be evoked following global illumination using a 405-nm laser (Fig. 4a) $(n=10$ recordings). Just over half (54\%) of the Fluo-2-loaded population responded to illumination with synchronous $\mathrm{Ca}^{2}+$ rises (Fig. 4a,b). Demonstrating the utility of JB253 for the fine control of beta cell function, discrete $\mathrm{Ca}^{2+}$ oscillations, thought to underlie generation of insulin pulses ${ }^{33,34}$, could be imposed using repeat exposure to $405 \mathrm{~nm}$ (Fig. 4c). As anticipated, high doses of tolbutamide and diazoxide were able to augment and suppress, respectively, the effects of JB253 (Fig. 4d,e) $(n=4-6$ recordings).

The wavelength required to excite Fluo-2 $(\lambda=491 \mathrm{~nm})$, a commonly used $\mathrm{Ca}^{2+}$ indicator, could potentially lead to $\mathrm{K}_{\mathrm{ATP}}$ channel closure in JB253-treated islets due to cis-isomer formation. We therefore decided to repeat the above experiments using the red $(\lambda=561 \mathrm{~nm})$-excited $\mathrm{Ca}^{2+}$ indicator X-Rhod1. Identical results were obtained for studies with Fluo-2 (Fig. 5a,b) (63\% responsive X-Rhod1-loaded cells) ( $n=3$ recordings), confirming that the photostationary state of JB253 during brief (263 ms) pulses of 491-nm light was alone insufficient to close $\mathrm{K}_{\mathrm{ATP}}$ channels in the islet preparation. Likewise, global $\mathrm{Ca}^{2+}$ oscillations could be induced in JB253-treated islets by more prolonged illumination with 440-nm and 491-nm laser lines and, as expected from the electrophysiological recordings, both wavelengths appeared to activate a slightly larger cell population (Fig. 5c,d). These observations were unlikely due to $\mathrm{K}_{\mathrm{ATP}}$ channel closure at $561 \mathrm{~nm}$, since JB253 was unable to photoswitch $\mathrm{K}^{+}$ currents at wavelengths $>560 \mathrm{~nm}$ (Supplementary Fig. 8).

Demonstrating the spatial precision of JB253, a single islet from a doublet could be activated using a targeting laser without significantly stimulating its neighbour $(\sim 200 \mu \mathrm{m}$ from center to center) (Fig. 5e), in part aided by the high molecular extinction coefficient $\left(38,670 \mathrm{~mol}^{-1} \mathrm{~cm}^{-1}\right.$ at $485 \mathrm{~nm}$; see Supplementary Fig. 9). Lastly, JB253 did not appear to be cytotoxic to islets, as necrosis indices showed no significant differences in cell death versus DMSO alone (Fig. 5f). 


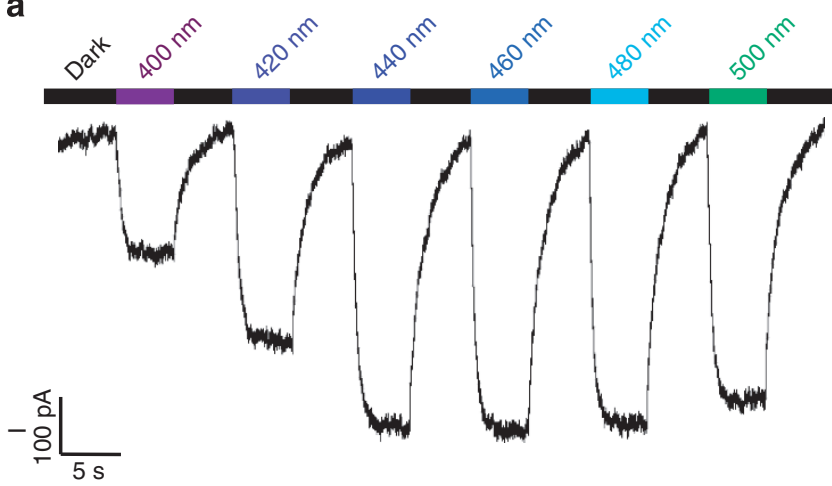

b
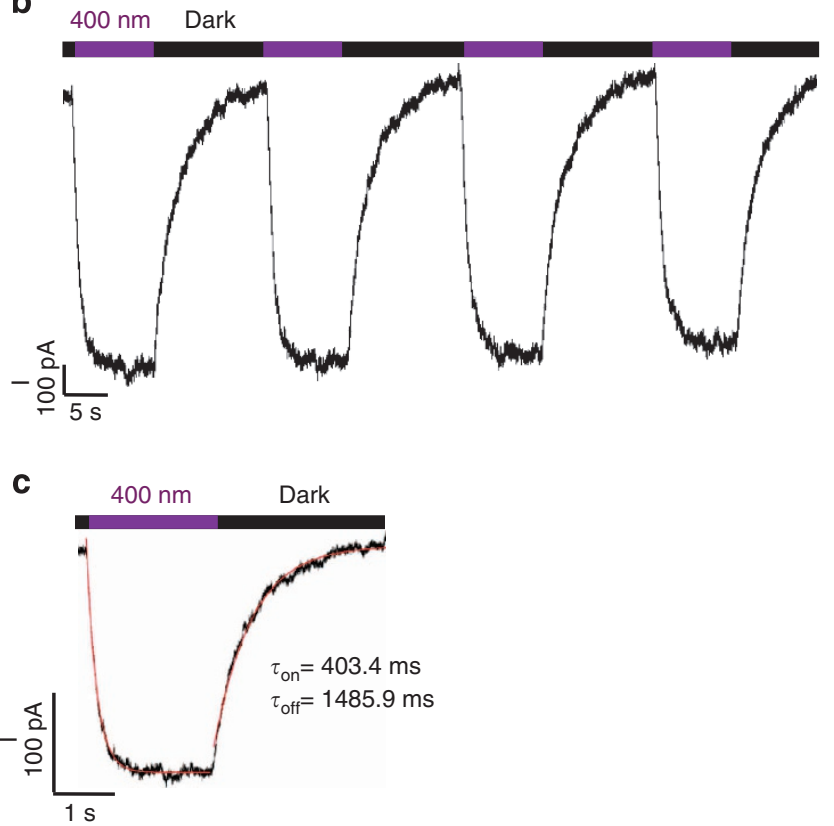

Figure 3 | JB253 confers photoswitching on $\mathrm{K}_{\text {ATP }}$ channels.

(a) Photocurrents recorded from HEK293t cells transfected with plasmids encoding Kir6.2 and SUR1 using the whole-cell patch-clamp configuration (holding potential $-60 \mathrm{mV}$ ). JB253-treated cells respond to wavelengths between 400 and $500 \mathrm{~nm}$ with a reduction in the magnitude of the $\mathrm{K}^{+}$ inward rectifier current. (b) JB253 allows reversible and repeated closure of $\mathrm{K}_{\text {ATP }}$ channels in response to light-dark cycles using $\lambda=400 \mathrm{~nm}$ to induce cis-isomerization (purple) and relaxation in the dark (black). (c) Kinetics of light-triggered block and thermal restoration of $\mathrm{K}_{\text {ATP }}$ channel currents mediated by JB253. In all cases, traces represent $n=4$ cells.

Manipulation of human islet function using JB253. To underline the translational potential of JB253 for use in man, $\mathrm{Ca}^{2+}$-imaging experiments were repeated using isolated human islets of Langerhans. As observed for their mouse counterparts, beta cells within JB253-treated human islets responded to 440 and $491 \mathrm{~nm}$ with large intracellular $\mathrm{Ca}^{2+}$ rises, and oscillations could be coaxed simply by turning the laser on and off (Fig. 6a-c). JB253 effects appeared to be due to $\mathrm{K}_{\mathrm{ATP}}$ blockade, as they could be mimicked and reversed using tolbutamide and diazoxide, respectively (Fig. 6c,d).

Optical stimulation of insulin release using JB253. To cement the link between photocontrol of $\mathrm{K}_{\mathrm{ATP}}$ channels, $\left[\mathrm{Ca}^{2+}\right]_{\mathrm{i}}$ and insulin secretion, islets (from $n=9$ mice) were incubated in the presence of JB253 while exposing to either dark (no illumination),
$405 \mathrm{~nm}$ or $485 \mathrm{~nm}$. Insulin release was similar in control experiments $(5 \mathrm{mM}$ glucose, shown to sensitize beta cells to sulfonylurea ${ }^{35}$ ) and JB253-treated islets in the dark, suggesting that any $\mathrm{K}_{\mathrm{ATP}}$ channel block and VDCC activity detected under these conditions was subthreshold for triggering $\mathrm{Ca}^{2+}$-activated exocytosis (Fig. 7). By contrast, JB253-treated islets secreted almost four- to eightfold more insulin following illumination, and this could be partially reversed using diazoxide (Fig. 7). When exposed to $485 \mathrm{~nm}$ light, JB253 was equipotent to glimepiride at stimulating insulin secretion (Fig. 7).

\section{Discussion}

In the present manuscript, we have described the development and testing of JB253, a chemical chimera of glimepiride and an azobenzene, which allows light-induced closure of $\mathrm{K}_{\mathrm{ATP}}$ channels. In the primary tissue employed here, viz islets of Langerhans, this translates to activated $\mathrm{Ca}^{2}+$ flux and insulin release.

The principles of photopharmacology, that is, the control of biological function with small-molecule photoswitches, are now well established ${ }^{25,36,37}$. In particular, azobenzene photoswitches have been employed as photochromic neurotransmitters and neuromodulators ${ }^{38,39}$, ion channel blockers ${ }^{24,40}$, covalently bound ion channel gates ${ }^{41}$ and enzyme inhibitors ${ }^{42,43}$. With respect to ion channels, however, they have mostly been used to optically control excitable cells in the mammalian nervous system, and none have directly targeted $\mathrm{K}_{\mathrm{ATP}}$ channels. These are ubiquitously expressed channels that contribute to membrane potential in a number of cell types including hypothalamic and hippocampal neurons, cardiac myocytes, vascular smooth muscle and neuroendocrine cells ${ }^{1,20-23,44}$. Importantly, $\mathrm{K}_{\mathrm{ATP}}$ channels translate metabolic state to transmembrane potential and, in pancreatic beta cells, are central to glucose-stimulated insulin secretion ${ }^{10-12}$. Since electrical status is generally correlated to biological output in excitable tissues, JB253 may provide a useful tool for investigating $\mathrm{K}_{\mathrm{ATP}}$ channel function under a range of normal and pathological states.

The prevailing view of sulfonylurea action is one of SUR1 binding, $K_{\mathrm{ATP}}$ channel closure and alterations to beta cell membrane potential ${ }^{7-9}$. However, recent studies have also invoked a $\mathrm{K}_{\mathrm{ATP}}$ channel-independent signalling pathway whereby sulfonylurea may alter insulin release via Epac2A interactions ${ }^{27-29}$. Using radioactive displacement assays in combination with FRET experiments, JB253 was found to interact with both SUR1 and Epac2A. While SUR1 affinity for JB253 was much lower than glimepiride, we were unable to properly assess the active cis-state due to rapid thermal backrelaxation. As such, a role for illumination in strengthening any interaction cannot be excluded, for example, by altering binding conformation due to isomerization. Nonetheless, JB253 and glimepiride possess similar $\mathrm{EC}_{50}$ values for intracellular $\mathrm{Ca}^{2+}$ rises and, when applied at the same concentration, both compounds stimulated almost identical levels of insulin secretion. Thus, JB253 possesses a similar activity profile to glimepiride, most likely due to signalling via pathways generally acknowledged to underlie sulfonylurea action.

In addition to photopharmacology, optogenetic and artificial light-sensitive $\mathrm{K}^{+}$channels are equally applicable to the remote control of electrically responsive cells, including beta cells ${ }^{45,46}$. However, therapeutic potential in humans is limited by the requirement for genetic manipulation, high activation irradiances and the hyperpolarizing effects of recombinantly expressed Kir6.2. Alternatively, an implantable synthetic optogenetic transcription device has recently been shown to improve bloodglucose homeostasis in a mouse model of T2DM via the expression and secretion of incretin ${ }^{47}$. However, debate still exists as to whether incretin-based therapies are associated with 
a
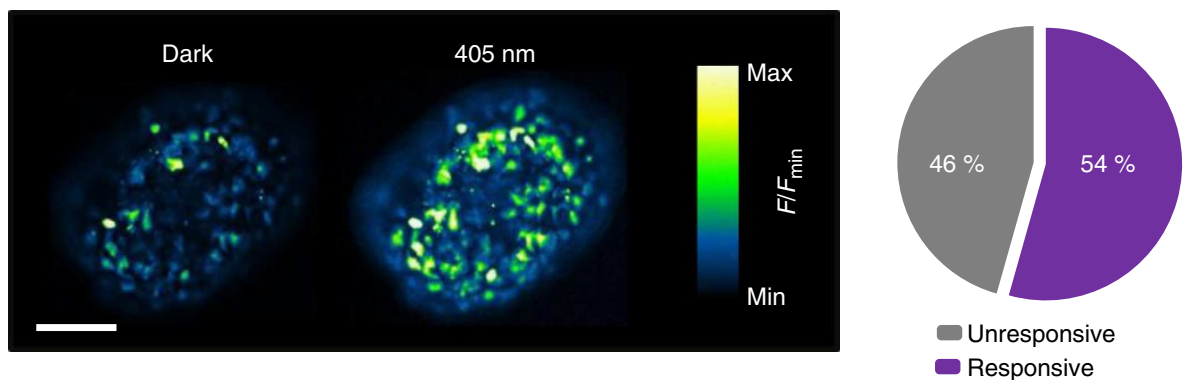

b

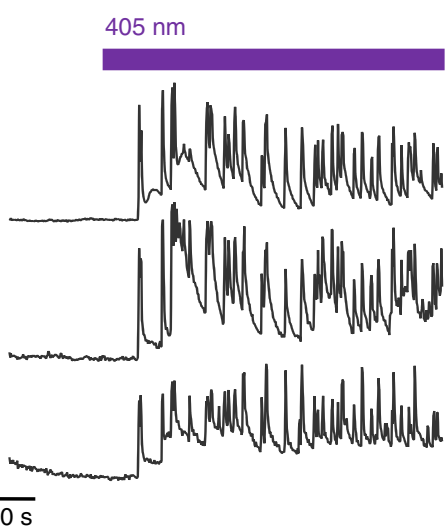

C

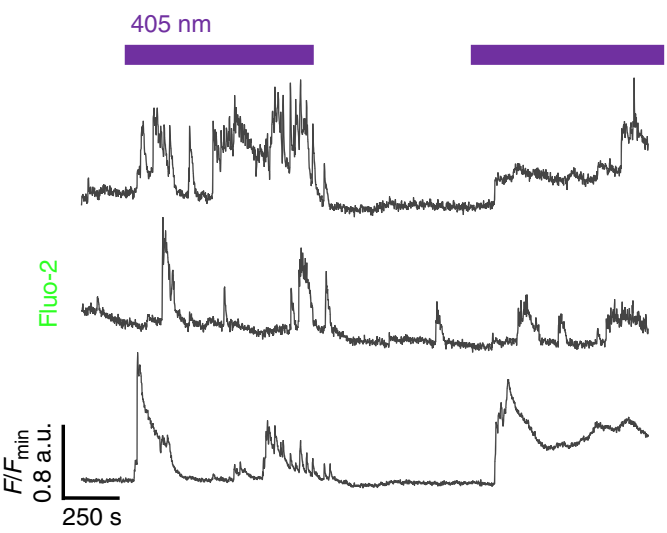

d

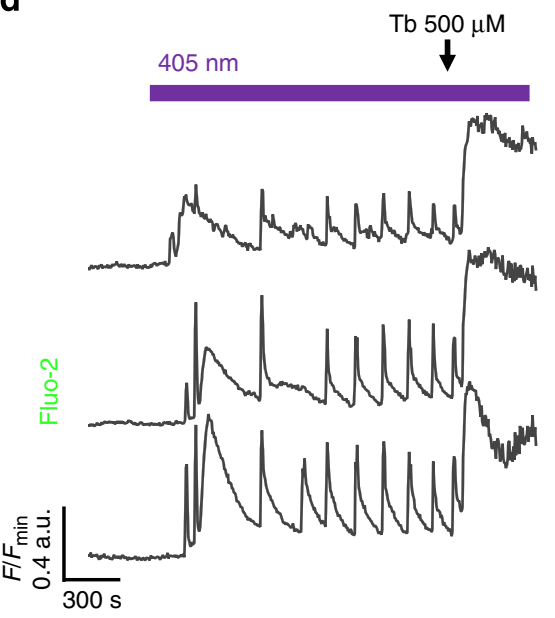

e

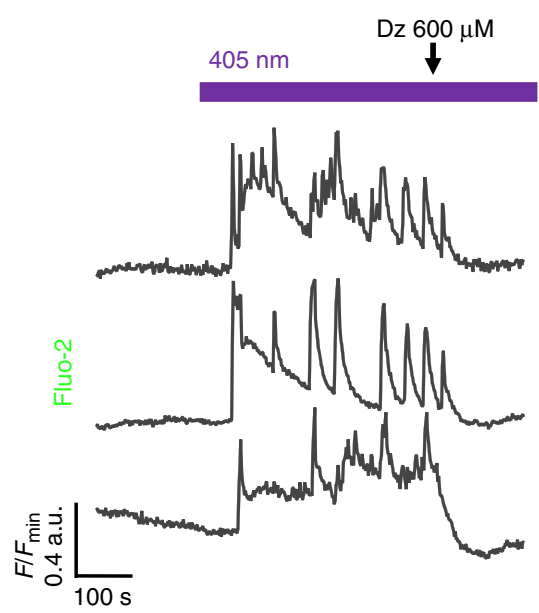

Figure 4 | JB253 allows optical manipulation of pancreatic beta cell activity. (a) Beta cells residing within JB253-treated islets display large increases in cytosolic $\mathrm{Ca}^{2+}$ following exposure to $405 \mathrm{~nm}$ (purple) (scale bar, $110 \mu \mathrm{m}$ ) (linear look up table (LUT)). (b) Illumination with $405 \mathrm{~nm}$ induces large and synchronous rises in $\mathrm{Ca}^{2+}$ as indicated by Fluo-2 (representative trace from $n=10$ recordings). (c) JB253 can be used to impose complex dynamics including $\mathrm{Ca}^{2+}$ oscillations (representative trace from $n=5$ recordings). (d) High-dose tolbutamide (Tb) augments the effects of JB253 on $\mathrm{K}_{\mathrm{ATP}}$ channel blockade (representative traces from $n=6$ recordings). (e) Diazoxide (Dz) inhibits JB253 effects by opening the K $K_{\text {ATP }}$ channel ion pore (representative traces from $n=4$ recordings).

increased risk of pancreatitis and pancreatic adenocarcinoma ${ }^{48,49}$. Nonetheless, similar concepts have recently been extended to designer fusion molecules and may in the future be adopted for insulin release ${ }^{50}$. By contrast, due to its favourable profile as an exogenously applied sulfonylurea that is sensitive to light, JB253 has advantages both as a research tool and as an anti-diabetic agent. We note, however, that confirmation of glucose-lowering effects in rodents is required before studies using JB253 can be extended to man.

In the context of photodynamic therapy, light penetration in human tissues has been studied in detail and is now well understood $^{51}$. Although, the current activation wavelength of
JB253 (400-500 nm) limits deep tissue penetration, for example, through the skin, we have recently begun to develop variants that can be switched at longer wavelengths. In addition, stimulated by the brisk development of optogenetics ${ }^{52}$, devices that can deliver light to target tissues with minimal invasiveness and high spatial precision have emerged ${ }^{53,54}$, although their application to the pancreas is untested.

We therefore speculate that JB253, or related photoswitchable molecules, which regulate $\mathrm{K}_{\mathrm{ATP}}$ channels, may have an impact on human medicine and research. A long-standing challenge in endocrinology has been the inability to properly recreate the dynamics that underlie pulsatile hormone release, a prerequisite 
a

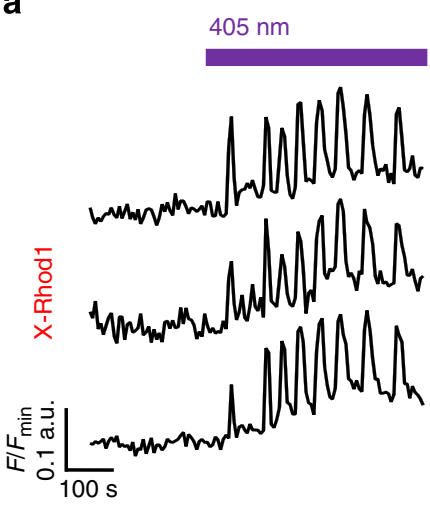

b

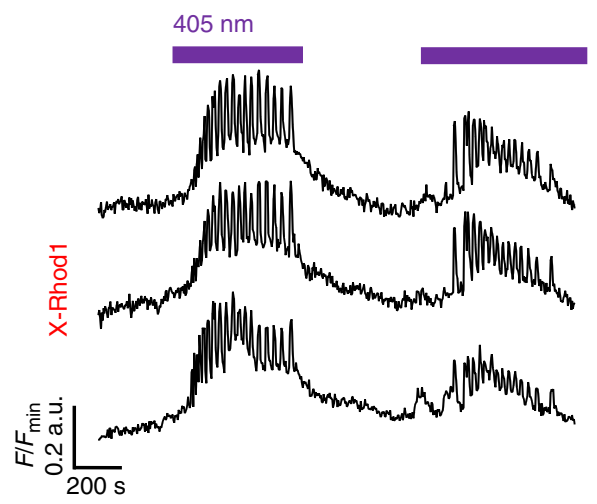

C

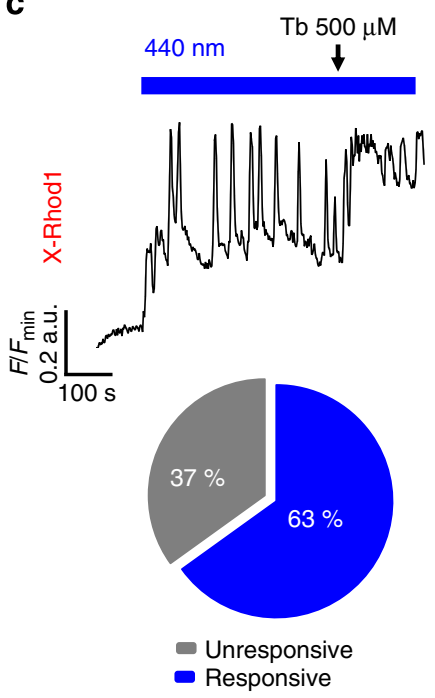

d

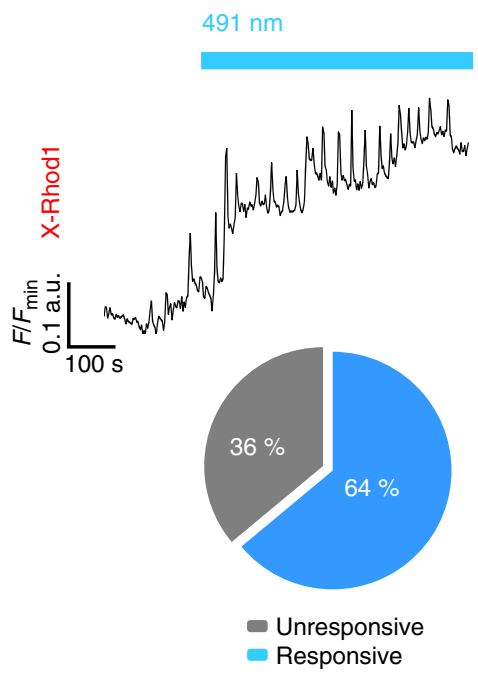

e

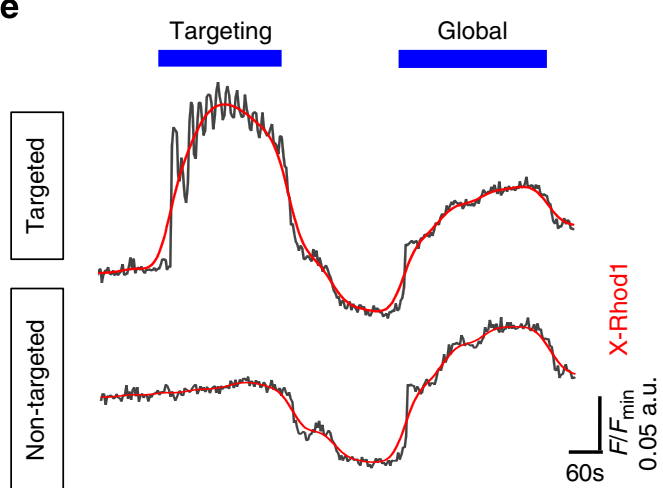

f

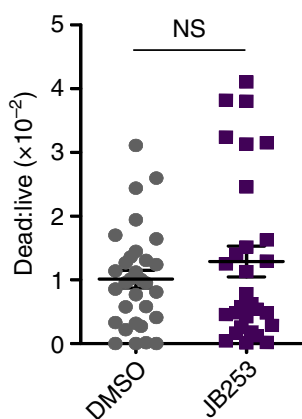

Figure 5 | Specific photoswitching of beta cell function in the violet-blue spectrum. (a) JB253-treated cells loaded with the red-shifted Ca ${ }^{2+}$ indicator X-Rhod1 ( $\lambda$ excitation $=561 \mathrm{~nm}$ ) similarly respond to $405 \mathrm{~nm}$ with $\mathrm{Ca}^{2+}$ rises (representative traces from $n=3$ recordings). (b) As in a, but imposition of oscillations (representative traces from $n=3$ recordings). (c) JB253-treated beta cells display large increases in cytosolic Ca ${ }^{2}+$ following exposure to $440 \mathrm{~nm}$ (representative trace from $n=6$ recordings). (d) As in c, but following illumination with $491 \mathrm{~nm}$ (Tb, tolbutamide; positive control) (representative trace from $n=5$ recordings). (e) A single islet can be photoswitched using a targeting laser while leaving its neighbour quiescent ( $~ 200 \mu \mathrm{m}$ center-center) (representative traces from $n=3$ recordings). A global laser pulse evokes activity in both islets (grey, raw; red, smoothed). (f) Incubation of islets with JB253 does not alter cell viability as assessed by calcein-AM and propidium iodide incorporation (NS, not significant versus DMSO alone, Student's t-test) ( $n=28$ islets from four animals). Values represent mean \pm s.e.m.

for proper downstream organ function ${ }^{55}$. Furthermore, disparate biological systems can use similar or identical molecular components. For example, $\mathrm{K}_{\mathrm{ATP}}$ channels are also expressed in the heart and brain, including in neuronal populations tasked with the central regulation of glucose homeostasis and counterregulatory responses ${ }^{20,56}$. Photopharmacology has the ability to target drug activity to the primary site of dysfunction with high spatial and temporal resolution ${ }^{37}$. JB253 holds particular promise in this regard. It is non-cytotoxic and can be used to repeatedly modulate rodent and human beta cell activity, the basis for recreating the oscillatory activity known to orchestrate hormone pulses ${ }^{33,34}$. Its light dependency means 
a

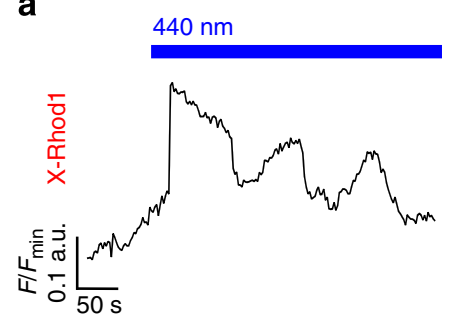

b

C

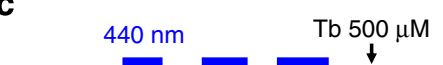

d
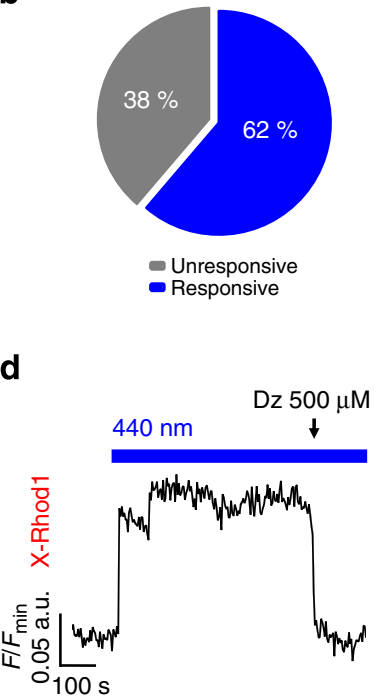

Figure 6 | Manipulation of human islet activity using JB253. (a) JB253treated beta cells residing within intact human islets respond to $440 \mathrm{~nm}$ with rapid rises in cytosolic $\mathrm{Ca}^{2}+$ levels (representative trace from $n=8$ recordings). (b) Almost $62 \%$ of X-Rhod1-loaded cells respond to JB253 with $\mathrm{Ca}^{2+}$ rises. (c) As in $\mathbf{a}$, but imposition of oscillations to demonstrate reversibility of JB253 effects in human tissue ( $\mathrm{Tb}$, tolbutamide; positive control) (representative trace from $n=4$ recordings). (d) Reversal of JB253 action using diazoxide to open the $\mathrm{K}_{\mathrm{ATP}}$ channel ion pore ( $\mathrm{Dz}$, diazoxide; negative control) (representative trace from $n=5$ recordings). In all cases, islets were derived from three donors.

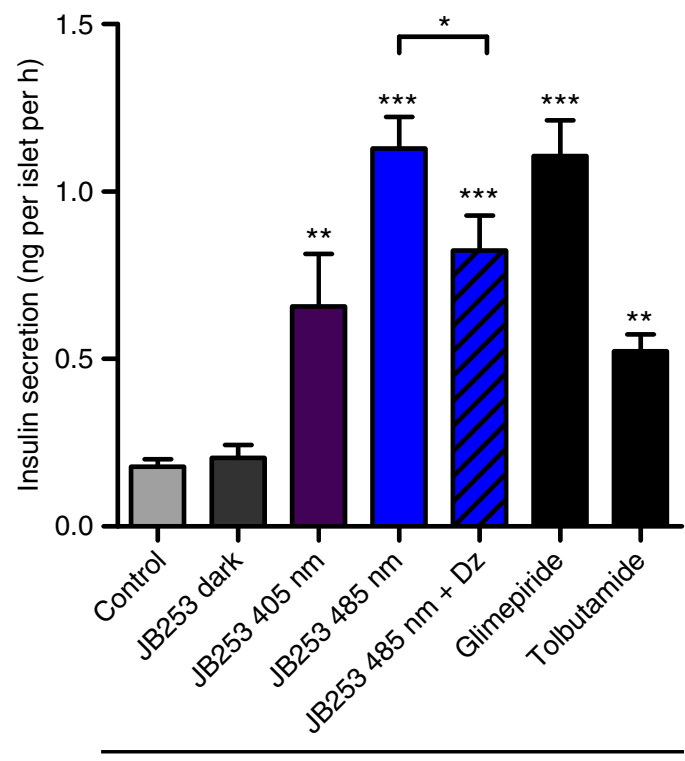

$5 \mathrm{mM}$ D-glucose

Figure 7 | JB253 yields optical control of insulin secretion. Application of JB253 under dark conditions is unable to influence insulin release versus control ( $5 \mathrm{mM}$ glucose alone; G5) during static incubation of isolated murine islets. By contrast, illumination with 405 and $485 \mathrm{~nm}$ significantly increases insulin secretion, and this is similar in magnitude to that achieved using glimepiride and tolbutamide $\left(n=9\right.$ mice) $\left({ }^{\star} P<0.05\right.$ versus JB253 $485 \mathrm{~nm} ;{ }^{\star \star} P<0.01$ and ${ }^{\star \star \star} P<0.001$ versus $\mathrm{G} 5$; one-way analysis of variance). Values represent mean \pm s.e.m.

that JB253 activity is spatially restricted by illumination, potentially reducing extra-pancreatic effects. Finally, the ability to 'turn on' or 'turn off JB253 action would allow insulin secretion to be tailored to peak demand. Therefore, pending thorough in vivo validation, JB253 and its congeners could potentially open up new avenues for the treatment of T2DM.

In summary, we have designed and synthesized a lightsensitive sulfonylurea, JB253, which has a broad spectrum of application due to conferment of photoswitching on $\mathrm{K}_{\mathrm{ATP}}$ activity.

\section{Methods}

Chemical synthesis. (E)-4-((4-(Diethylamino)phenyl)diazenyl)benzenesulfonamide (1). Sulfanilamide $(2.00 \mathrm{~g}, 11.61 \mathrm{mmol}, 1.0 \mathrm{eq}$.) was dissolved in $2.4 \mathrm{M} \mathrm{HCl}$ and cooled to $0{ }^{\circ} \mathrm{C}$. Under vigorous stirring, a solution of $\mathrm{NaNO}_{2}(0.96 \mathrm{~g}, 13.91 \mathrm{mmol}, 1.2$ eq.) in $6 \mathrm{ml}$ water was added dropwise until the solution turned pale yellow. The formed diazonium salt was stirred under ice-cooling for an additional $10 \mathrm{~min}$ before it was transferred into a solution of $N, N$-diethylaniline $(1.73 \mathrm{~g}, 11.61 \mathrm{mmol}, 1.84 \mathrm{ml}$ 1.0 eq.) in a $1 / 1$ mixture of $1 \mathrm{M} \mathrm{NaOAc/MeOH}$. The solution turned to dark red and was allowed to warm to room temperature under stirring. The crude product was extracted with EtOAc (3x), and the combined organic layers were washed with brine and dried over $\mathrm{MgSO}_{4}$. Flash column chromatography (25\% EtOAc/i-hexanes) yielded $1.45 \mathrm{~g}(4.37 \mathrm{mmol})$ of the desired product as a red powder in $38 \%$ yield. ${ }^{1} \mathrm{H}$ NMR $\left(400 \mathrm{MHz}\right.$, DMSO-d $\left.\mathrm{d}_{6}\right): \delta$ (p.p.m.) $=7.95(\mathrm{~d}, J=8.6 \mathrm{~Hz}, 2 \mathrm{H}), 7.88(\mathrm{~d}, J=8.6$ $\mathrm{Hz}, 2 \mathrm{H}), 7.81(\mathrm{~d}, J=9.2 \mathrm{~Hz}, 2 \mathrm{H}), 7.45(\mathrm{~s}, 2 \mathrm{H}), 6.82(\mathrm{~d}, J=9.3 \mathrm{~Hz}, 2 \mathrm{H}), 3.47$ $(\mathrm{q}, J=7.0 \mathrm{~Hz}, 4 \mathrm{H}), 1.15(\mathrm{t}, J=7.0 \mathrm{~Hz}, 6 \mathrm{H}) .{ }^{13} \mathrm{C}$ NMR $\left(101 \mathrm{MHz}, \mathrm{DMSO}-\mathrm{d}_{6}\right): \delta$ (p.p.m.) $=154.2,150.8,143.8,142.2,126.9,125.8,121.9,111.1,44.2,12.5$. Highresolution mass spectrometry (electrospray ionization): calc. for $\mathrm{C}_{16} \mathrm{H}_{21} \mathrm{~N}_{4} \mathrm{O}_{2} \mathrm{~S}^{+}$ $(\mathrm{M}+\mathrm{H})^{+}: 333.1380$, found: 333.1377 . $R_{\mathrm{t}}$ (liquid chromatography-mass spectrometry (LC-MS); $\mathrm{MeCN} / \mathrm{H}_{2} \mathrm{O} /$ formic acid $=10 / 90 / 0.1 \rightarrow 90 / 10 / 0.1$ over

$7 \mathrm{~min})=4.364 \mathrm{~min}$. Ultraviolet $/ \mathrm{Vis}(\mathrm{LC}-\mathrm{MS}): \lambda_{\max }=460 \mathrm{~nm}$.

(E)-N-(Cyclohexylcarbamoyl)-4-((4-(diethylamino)phenyl)diazenyl)benzenesulfonamide (JB253). A mixture of (E)-4-((4-(diethylamino)phenyl)diazenyl) benzenesulfonamide ( $332 \mathrm{mg}, 1.0 \mathrm{mmol}, 1.0$ eq.) and $\mathrm{Cs}_{2} \mathrm{CO}_{3}(1.30 \mathrm{~g}, 4.0 \mathrm{mmol}, 4.0$ eq.) in acetone $(20 \mathrm{ml})$ was refluxed for $1 \mathrm{~h}$ before addition of cyclohexyl isocyanate ( $125 \mathrm{mg}, 1.0 \mathrm{mmol}, 119 \mu \mathrm{l}, 1.0$ eq.) diluted in acetone $(20 \mathrm{ml})$. The reaction mixture was refluxed for an additional $3 \mathrm{~h}$, before cooling to $\sim 40^{\circ} \mathrm{C}$. The crude solid was filtered and washed with small amounts of acetone before it was carefully dissolved in $\mathrm{MeOH}$ to yield $450 \mathrm{mg}(0.98 \mathrm{mmol})$ of JB253 product in $98 \%$ yield. ${ }^{1} \mathrm{H}$ NMR $\left(400 \mathrm{MHz}, \mathrm{DMSO}-\mathrm{d}_{6}\right): \delta$ (p.p.m.) $=7.83(\mathrm{~d}, J=8.5 \mathrm{~Hz}, 2 \mathrm{H}), 7.78(\mathrm{~d}, J=9.1 \mathrm{~Hz}$ $2 \mathrm{H}), 7.69$ (d, $J=8.5 \mathrm{~Hz}, 2 \mathrm{H}), 6.80(\mathrm{~d}, J=9.3 \mathrm{~Hz}, 2 \mathrm{H}), 5.62$ (br s, 2H), 3.46 (q, $J=7.0 \mathrm{~Hz}, 4 \mathrm{H}), 3.20$ (br s, $1 \mathrm{H}), 1.86-1.38(\mathrm{~m}, 5 \mathrm{H}), 1.33-0.92(\mathrm{~m}, 11 \mathrm{H}) .{ }^{13} \mathrm{C}$ NMR $\left(101 \mathrm{MHz}, \mathrm{DMSO}-\mathrm{d}_{6}\right): \delta$ (p.p.m.) $=172.7$ (heteronuclear multiple-bond correlation (HMBC), see Supplementary Fig. 4), 152.6, 150.2, 148.5, 142.2, 127.4, 125.3, 120.8 $111.0,47.8,44.1,33.5,25.5,24.9,12.5$. High-resolution mass spectrometry (electrospray ionization): calc. for $\mathrm{C}_{23} \mathrm{H}_{32} \mathrm{~N}_{5} \mathrm{O}_{3} \mathrm{~S}^{+}(\mathrm{M}+\mathrm{H})^{+}: 458.2220$, found: 458.2219. $R_{\mathrm{t}}$ (LC-MS; MeCN/ $\mathrm{H}_{2} \mathrm{O} /$ formic acid $=10 / 90 / 0.1 \rightarrow 90 / 10 / 0.1$ over $7 \mathrm{~min})=5.285 \mathrm{~min}$. Ultraviolet $/ \mathrm{Vis}\left(100 \mu \mathrm{M}\right.$ in DMSO): $\lambda_{\max }=472 \mathrm{~nm}$; (LC-MS): $\lambda_{\max }=468 \mathrm{~nm} . \varepsilon_{405 \mathrm{~nm}}=18,501 \mathrm{~mol}^{-1} \mathrm{~cm}^{-1} ; \varepsilon_{485 \mathrm{~nm}}=38,670 \mathrm{~mol}^{-1} \mathrm{~cm}^{-1}$. Infrared (attenuated total reflectance): wavenumber in $\mathrm{cm}^{-1}=3331,2928,2851$, $1652,1626,1602,1576,1537,1514,1390,1349,1174,1130,1086,1042,843,820$, 676. m.p. $=190^{\circ} \mathrm{C}$

General chemistry. Flash column chromatography was carried out on silica gel $60(0.040-0.063 \mathrm{~mm})$ purchased from Merck. Reverse phase flash column chromatography was carried out on Waters C18 silica gel $(0.055-0105 \mathrm{~mm}, 125 \AA$ ). Reactions and chromatography fractions were monitored by thin-layer chromatography on Merck silica gel 60 F254 glass plates. The spots were visualized either under ultraviolet light at $254 \mathrm{~nm}$ or with appropriate staining method (iodine, p-anisaldehyde, $\mathrm{KMnO}_{4}$ ) followed by heating.

NMR spectra were recorded in deuterated solvents on Varian Mercury 200, Bruker AXR 300, Varian VXR 400S, Bruker AMX 600 and Bruker Avance III HD 400 (equipped with a CryoProbe) instruments and calibrated to residual solvent peaks $\left({ }^{1} \mathrm{H} /{ }^{13} \mathrm{C}\right.$ in p.p.m.): DMSO- $\mathrm{d}_{6}(2.50 / 39.52)$. Multiplicities are abbreviated as follows: $\mathrm{s}=$ singlet, $\mathrm{d}=$ doublet, $\mathrm{t}=$ triplet, $\mathrm{q}=$ quartet, $\mathrm{br}=$ broad and $\mathrm{m}=$ multiplet. Spectra are reported based on appearance, not on theoretical multiplicities derived from structural information.

A Varian MAT CH7A mass spectrometer was used to obtain low- and highresolution electron impact mass spectra. Low- and high-resolution ESI mass spectra were obtained on a Varian MAT 711 MS instrument operating in either positive or negative ionization modes.

Solvents for column chromatography and reactions were purchased in HPLC grade or distilled over an appropriate drying reagent before use. If necessary, solvents were degassed either by freeze-pump-thaw or by bubbling $\mathrm{N}_{2}$ through the vigorously stirred solution for several minutes. Unless otherwise stated, all other reagents were used without further purification from commercial sources.

Ultraviolet/Vis spectra were recorded on a Varian Cary 50 Bio UV-Visible Spectrophotometer using Helma Suprasil precision cuvettes (10 $\mathrm{mm}$ light path).

LC-MS was performed on an Agilent 1260 Infinity HPLC System, MS-Agilent 1100 Series, Type: 1946D, Model: SL, equipped with a Agilent Zorbax Eclipse Plus $\mathrm{C} 18(100 \times 4.6 \mathrm{~mm}$, particle size 3.5 micron $) \mathrm{RP}$ column. 
Infrared spectra were recorded on a PerkinElmer Spectrum BX-59343 instrument as neat materials. For detection, a Smiths Detection DuraSam-plIR II Diamond ATR sensor was used. The measured wavenumbers are reported in $\mathrm{cm}^{-1}$.

Melting points were measured on an EZ-Melt apparatus (Stanford Research Systems) and are uncorrected.

Extinction coefficients were measured on a BMG Labtech Omega Series FLUOstar microplate reader with clear flat-bottom white 96-well plates by full spectra acquirement in low- $\mathrm{K}^{+}$external bath buffer (containing in mM: $3 \mathrm{KCl}, 118$ $\mathrm{NaCl}, 25 \mathrm{NaHCO}_{3}, 2 \mathrm{CaCl}_{2}, 1 \mathrm{MgCl}_{2}, 10$ HEPES; $\mathrm{NaOH}$ to $\mathrm{pH}$ 7.4). All JB253containing solutions (dilution series, $n=4: 10 \mathrm{nM} ; 100 \mathrm{nM} ; 1 \mu \mathrm{M} ; 10 \mu \mathrm{M} ; 25 \mu \mathrm{M}$; $50 \mu \mathrm{M})$ were background substracted and fitted with a linear slope. Volumes were $100 \mu \mathrm{l}$ each, which resulted in a path length of $l=2.94 \mathrm{~mm}$. $p K_{a}$ measurements and data processing were performed using the same instrument and protocol as in the study by Martinez and Dardonville $e^{57}$. Full absorbance spectra $(280-800 \mathrm{~nm})$ were acquired and background subtracted before spectral differences were calculated. The total change of maximal positive and maximal negative difference was calculated and plotted against $\mathrm{pH}$. Sigmoidal fit of the obtained plot gave access to the $p K_{a}$.

Crystallography. X-Ray data collection was performed on a Bruker D8Venture at $173 \mathrm{~K}$ using MoK $\alpha$-radiation $(\lambda=0.71073 \AA)$. The APEX2 (v2012.4-3, Bruker AXS Inc.) software and embedded programs were applied for the integration, scaling and multi-scan absorption correction of the data. The structures were solved by direct methods with SIR $97^{58}$ and refined by least-squares methods against F2 with SHELXL- $97^{59}$. All non-hydrogen atoms were refined anisotropically. The C-bound hydrogen atoms were placed in ideal geometry riding on their parent atoms, $N$-bound hydrogen atoms were refined freely. The crystallographic data for JB253 is available free of charge from The Cambridge Crystallographic Data Centre via www.ccdc.cam.ac.uk/data_request/cif (accession ref. CCDC 1014606).

Electrophysiology. HEK293t cells (obtained from the Leibniz-Institut DSMZ: \#305) were incubated in Dulbecco's modified Eagle's medium $+10 \%$ foetal bovine serum and used for electrophysiological recordings $24-48 \mathrm{~h}$ following Lipofectamine transfection with plasmids encoding Kir6.2 (Genbank D50581), rat SUR1 (Genbank L40624) and green fluorescent protein. Whole-cell patch-clamp experiments were performed using a standard electrophysiology setup equipped with a HEKA Patch Clamp EPC10 USB amplifier and PatchMaster software (HEKA Electronik). Micropipettes were generated from 'Science Products GB200F-8P with filament' pipettes using a vertical puller. Resistance varied between 5 and $7 \mathrm{M} \Omega$. Bath solution contained in mM: $3 \mathrm{KCl}, 118 \mathrm{NaCl}, 25 \mathrm{NaHCO}_{3}, 2 \mathrm{CaCl}_{2}, 1$ $\mathrm{MgCl}_{2}, 10$ HEPES ( $\mathrm{NaOH}$ to $\mathrm{pH} 7.4$ ). Pipette solution contained in $\mathrm{mM}: 90 \mathrm{~K}-$ gluconate, $10 \mathrm{NaCl}, 10 \mathrm{KCl}, 1 \mathrm{MgCl}_{2}, 10 \mathrm{EGTA}, 60 \mathrm{HEPES}$ (KOH to $\mathrm{pH} 7.3$ ), and the holding potential was $-60 \mathrm{mV}$. Illumination during electrophysiology and ultraviolet/Vis experiments was provided by a TILL Photonics Polychrome 5000 monochromator. JB253 was applied at $50 \mu \mathrm{M}$, as this concentration was found to be maximal for stimulating $\mathrm{Ca}^{2+}$ rises.

MIN6 cells (a kind gift from Dr Jun-ichi Miyazaki, Osaka University) were cultured in Dulbecco's modified Eagle's medium supplemented with 15\% foetal bovine serum, $1 \%$ glutamine, $2 \%$ HEPES buffer, $0.0005 \% \beta$-mercaptoethanol and $1 \%$ penicillin/streptomycin. Cells were seeded onto glass coverslips $24 \mathrm{~h}$ before whole-cell patch-clamp experiments using micropipettes generated from thinwalled borosilicate capillaries (3-6 M $)$ ). Bath solution contained in mM: $3 \mathrm{KCl}$, $118 \mathrm{NaCl}, 25 \mathrm{HEPES}, 3 \mathrm{MgCl}_{2}$ and $2 \mathrm{CaCl}_{2}$. Pipette solution contained in $\mathrm{mM}$ : $150 \mathrm{KCl}, 3 \mathrm{MgCl}_{2}$, 5 EGTA, 10 HEPES, $0.3 \mathrm{~K}_{2} \mathrm{ATP}$ (pH 7.2), and the holding potential was $-60 \mathrm{mV}$. Illumination was provided using a X-Cite 120 mercury arc lamp (Lumen Dynamics) with a bandpass filter $(470 \pm 20 \mathrm{~nm})$. Voltage ramps from $-20 \mathrm{mV}$ to $-120 \mathrm{mV}$ ( $500 \mathrm{~ms}$ duration) were applied every $5 \mathrm{~s}$ to produce current-voltage relationships in the presence and absence of JB253. All cells lines were regularly mycoplasma tested.

Mouse islet isolation. Male and female CD1 and C57BL6 mice (8-20 weeks) were maintained in a specific pathogen-free facility under a $12 \mathrm{~h}$ light-dark cycle with $a d$ libitum access to water and food. Animals were euthanized using a schedule-1 method and pancreatic islets isolated by collagenase digestion. All procedures were regulated by the Home Office according to the Animals (Scientific Procedures) Act 1986 of the United Kingdom (PPL 70/7349), and study approval granted by the Animal Welfare and Ethical Review Body of Imperial College. No randomization was used for animal experimentation, since mice were only used as tissue donors.

Human islet isolation. Human islets were isolated from deceased heart-beating donors $(n=3)$ at transplantation facilities in Pisa and Edmonton with the relevant national and local ethical permissions, including consent from next of kin where required, and cultured in Roswell Park Memorial Institute medium supplemented with $5.5 \mathrm{mM}$ D-glucose, $10 \%$ foetal calf serum, $100 \mathrm{U} / \mathrm{ml}$ penicillin, $100 \mu \mathrm{g} / \mathrm{ml}$ streptomycin and $0.25 \mu \mathrm{g} / \mathrm{ml}$ fungizone $\left(37^{\circ} \mathrm{C}, 5 \% \mathrm{CO}_{2}\right)$. All studies involving human tissue were approved by the National Research Ethics Committee London (Fulham), REC \#07/H0711/114.
Calcium imaging. Islets were loaded for $30-45 \mathrm{~min}$ in Fluo2-AM $(10 \mu \mathrm{M})$ or for $2-$ 5 min with X-Rhod $1(5 \mu \mathrm{M})$ diluted with a mixture of DMSO $(0.01 \%$, wt $/ \mathrm{vol})$ and pluronic acid $(0.001 \%$, wt $/ \mathrm{vol}$; all Invitrogen) in a bicarbonate buffer containing in mM: $120 \mathrm{NaCl}, 4.8 \mathrm{KCl}, 1.25 \mathrm{NaH}_{2} \mathrm{PO}_{4}, 24 \mathrm{NaHCO}_{3}, 2.5 \mathrm{CaCl}_{2}, 1.2 \mathrm{MgCl}_{2}$ and 5 D-glucose. Functional multicellular $\mathrm{Ca}^{2+}$ imaging was performed using a Zeiss Axiovert M200 fitted with a Nipkow spinning-disk head (Yokogawa CSU-10) and a $\times 10 / 0.3$ numerical apperture objective adjusted for chromatic aberration (EC Plan-Neofluar, Zeiss). Pulsed excitation (frequency $=0.5 \mathrm{~Hz}$; exposure $=263$ ms) was delivered at $491 \mathrm{~nm}$ and emitted signals recorded at $500-550 \mathrm{~nm}$ with a back-illuminated 16-bit EM-CCD camera (ImageEM 9100-13; Hamamatsu). During recording, islets were maintained at $35-36^{\circ} \mathrm{C}$ in the presence of $50 \mu \mathrm{M}$ JB253 using a custom-manufactured perfusion and heating system (Digital Pixel). Drugs were introduced through the perfusion system at the indicated time points and concentrations. Violet light was delivered by a $405 \pm 5$-nm laser coupled to the side port of the microscope and configured to fill the back of the objective with light using an Optospot (Cairn Research). Blue light was delivered using $440 \pm 5$ $\mathrm{nm}$ and $491 \pm 5$-nm diode lasers controlled by a laser merge module (Spectral Applied Research) to allow simultaneous exposure and acquisition. For single islet targeting, a $473 \pm 5 \mathrm{~nm}$ laser was coupled to a custom-manufactured dichroic array (Cairn Research), allowing user-directed steering of a collimated laser spot across the field of view. Signals were normalized using $F / F_{\min }$ where $F$ is fluorescence at a given time point and $F_{\min }$ is minimum fluorescence.

Cytotoxicity assay. Islets were incubated with either DMSO or JB253 for $1 \mathrm{~h}$ before staining with $3 \mu \mathrm{M}$ of calcein-AM (live) and $2.5 \mu \mathrm{M}$ of propidium iodide (dead). Absorbance/emission was detected at $491 / 525$ and $561 / 620 \mathrm{~nm}$ for calcein and PI, respectively. The area of dead:live cells was calculated as a unitary ratio and the observer blinded to treatment identity.

Epac2 imaging. For Epac2 imaging, HEK293t were transfected with the full-length construct for Epac2-camps containing the cAMP- and sulfonylurea-binding domains ${ }^{29}$ (a kind gift from Prof. Jin Zhang, Johns Hopkins University) before imaging $^{60}$ using a HEPES-bicarbonate buffer containing in mM: $120 \mathrm{NaCl}, 4.8 \mathrm{KCl}$, $24 \mathrm{NaHCO}_{3}, 0.5 \mathrm{Na}_{2} \mathrm{HPO}_{4}, 5$ HEPES, $2.5 \mathrm{CaCl}_{2}, 1.2 \mathrm{MgCl}_{2}$ and 5 D-glucose. Excitation was delivered at $440 \mathrm{~nm}$ and emitted signals captured using cerulean $(530 \mathrm{~nm})$ and citrine $(470 \mathrm{~nm})$ filters. FRET was calculated as the ratio of Cerulean (CFP):Venus (YFP) fluorescence. Signals were normalized using $R / R_{\mathrm{o}}$, where $R$ is the ratio at a given time point and $R_{\mathrm{o}}$ is the minimum ratio.

Measurements of insulin secretion from isolated islets. Insulin secretion was measured from six islets per well, incubated at $37^{\circ} \mathrm{C}$ for $30 \mathrm{~min}$ in $0.5 \mathrm{ml}$ of Krebs-HEPES-bicarbonate solution (containing in mM: $130 \mathrm{NaCl}, 3.6 \mathrm{KCl}, 1.5$ $\mathrm{CaCl}_{2}, 0.5 \mathrm{MgSO}_{4}, 0.5 \mathrm{NaH}_{2} \mathrm{PO}_{4}, 2 \mathrm{NaHCO}_{3}, 10$ HEPES and $0.1 \%$ (wt/vol) bovine serum albumin, $\mathrm{pH}$ 7.4) containing the indicated glucose concentration and tolbutamide $(100 \mu \mathrm{M})$, glimepiride $(50 \mu \mathrm{M})$, diazoxide $(250 \mu \mathrm{M})$ and JB253 $(50 \mu \mathrm{M})$. Illumination $(\lambda=405 \pm 20 \mathrm{~nm}$ and $485 \pm 6 \mathrm{~nm})$ was performed using a Fluostar Optima microplate reader (BMG Labtech) set to deliver $30 \mathrm{~s}$ of light every $2 \mathrm{~min}$ to the designated wells. Insulin concentrations were determined in duplicate using specific radioimmunoassay (EMD Millipore).

[3H]-Glibenclamide radioassay. SUR1-expressing HEK293t cells were harvested and washed twice in assaying buffer containing in $\mathrm{mM}: 119 \mathrm{NaCl}, 4.7 \mathrm{KCl}, \mathrm{mM}$ $\mathrm{CaCl}_{2}, 1.2 \mathrm{KH}_{2} \mathrm{PO}_{4}, 1.2 \mathrm{MgSO}_{4}, 5 \mathrm{NaHCO}_{3}$ and $20 \mathrm{HEPES}, \mathrm{pH}$ 7.4. In a 96-well plate, $\sim 200,000$ cells per well were incubated for 50 min with [3H]-glibenclamide (PerkinElmer) and different concentrations of glimepiride (Sigma-Aldrich) or JB253. Incubation was terminated by rapid filtration through Whatman GF/C filters by means of a Brandel MWXR-96 TI harvester and filters were washed three times with ice-cold assay buffer. Radioactivity was counted $6 \mathrm{~h}$ after cell and filter lysis in $200 \mu$ l Rotiszint EcoPlus (Roth) using a Packard microbeta scintillation counter (PerkinElmer).

Statistical analysis. Data distribution was determined using the D'Agostino omnibus test. Non-multifactorial pairwise comparisons were made using the Student's $t$-test. Interactions between multiple treatments were assessed using one-way analysis of variance followed by pairwise comparisons using Bonferroni's post hoc test. Nonlinear regression was used to calculate the $\mathrm{EC}_{50}$ of normalized and log-transformed concentration-response curves. For [3H]-glibenclamide displacement assays, data points were fitted to the Hill equation before calculation of the halfmax value. In all cases, analysis was performed using Graphpad Prism (Graphpad Software) and IgorPro, and experimental numbers reported as independent biological replicates. No animals or data were excluded from the analysis and results were considered significant at $P<0.05$. Effect sizes in islets/cells are usually sufficiently large that multiple animals/independent replication is a more important determinant of power in studies requiring statistical comparison. 


\section{References}

1. Currie, C. J., Poole, C. D. \& Gale, E. A. The influence of glucose-lowering therapies on cancer risk in type 2 diabetes. Diabetologia 52, 1766-1777 (2009).

2. Stitt, A. W. AGEs and diabetic retinopathy. Invest. Ophthalmol. Vis. Sci. 51, 4867-4874 (2010)

3. Prentki, M. \& Nolan, C. J. Islet beta cell failure in type 2 diabetes. J. Clin. Invest. 116, 1802-1812 (2006).

4. Turner, R. C., Cull, C. A., Frighi, V. \& Holman, R. R. Glycemic control with diet, sulfonylurea, metformin, or insulin in patients with type 2 diabetes mellitus: progressive requirement for multiple therapies (UKPDS 49). UK Prospective Diabetes Study (UKPDS) Group. JAMA 281, 2005-2012 (1999)

5. Fineman, M. S. et al. Effect on glycemic control of exenatide (synthetic exendin-4) additive to existing metformin and/or sulfonylurea treatment in patients with type 2 diabetes. Diabetes Care 26, 2370-2377 (2003).

6. Inzucchi, S. E. et al. Management of hyperglycemia in type 2 diabetes: a patientcentered approach: position statement of the American Diabetes Association (ADA) and the European Association for the Study of Diabetes (EASD). Diabetes Care 35, 1364-1379 (2012).

7. Ashcroft, F. M. \& Gribble, F. M. Correlating structure and function in ATPsensitive K+ channels. Trends Neurosci. 21, 288-294 (1998).

8. Aguilar-Bryan, L. et al. Toward understanding the assembly and structure of KATP channels. Physiol. Rev. 78, 227-245 (1998).

9. Miki, T., Nagashima, K. \& Seino, S. The structure and function of the ATPsensitive $\mathrm{K}+$ channel in insulin-secreting pancreatic beta-cells. J. Mol. Endocrinol. 22, 113-123 (1999).

10. Ashcroft, F. M. \& Gribble, F. M. ATP-sensitive K+ channels and insulin secretion: their role in health and disease. Diabetologia 42, 903-919 (1999).

11. Seino, S. \& Miki, T. Physiological and pathophysiological roles of ATP-sensitive K+ channels. Prog. Biophys. Mol. Biol. 81, 133-176 (2003).

12. Rutter, G. A. Nutrient-secretion coupling in the pancreatic islet beta-cell: recent advances. Mol. Aspects Med. 22, 247-284 (2001).

13. Rorsman, P., Braun, M. \& Zhang, Q. Regulation of calcium in pancreatic alphaand beta-cells in health and disease. Cell Calcium 51, 300-308 (2012).

14. Henquin, J. C. Regulation of insulin secretion: a matter of phase control and amplitude modulation. Diabetologia 52, 739-751 (2009).

15. Tsuboi, T. \& Rutter, G. A. Multiple forms of 'kiss-and-run' exocytosis revealed by evanescent wave microscopy. Curr. Biol. 13, 563-567 (2003).

16. Cheatham, B. \& Kahn, C. R. Insulin action and the insulin signaling network. Endocr. Rev. 16, 117-142 (1995).

17. Jennings, A. M., Wilson, R. M. \& Ward, J. D. Symptomatic hypoglycemia in NIDDM patients treated with oral hypoglycemic agents. Diabetes Care 12, 203-208 (1989).

18. Evans, J. M., Ogston, S. A., Emslie-Smith, A. \& Morris, A. D. Risk of mortality and adverse cardiovascular outcomes in type 2 diabetes: a comparison of patients treated with sulfonylureas and metformin. Diabetologia 49, 930-936 (2006).

19. Nathan, D. M. et al. Management of hyperglycemia in type 2 diabetes: a consensus algorithm for the initiation and adjustment of therapy: a consensus statement from the American Diabetes Association and the European Association for the Study of Diabetes. Diabetes Care 29, 1963-1972 (2006).

20. Lam, T. K. Neuronal regulation of homeostasis by nutrient sensing. Nat. Med. 16, 392-395 (2010)

21. Hernandez-Sanchez, C. et al. Mice transgenically overexpressing sulfonylurea receptor 1 in forebrain resist seizure induction and excitotoxic neuron death. Proc. Natl Acad. Sci. USA 98, 3549-3554 (2001).

22. Engler, R. L. \& Yellon, D. M. Sulfonylurea KATP blockade in type II diabetes and preconditioning in cardiovascular disease. Time for reconsideration. Circulation 94, 2297-2301 (1996)

23. Quayle, J. M., Nelson, M. T. \& Standen, N. B. ATP-sensitive and inwardly rectifying potassium channels in smooth muscle. Physiol. Rev. 77, 1165-1232 (1997).

24. Fortin, D. L. et al. Photochemical control of endogenous ion channels and cellular excitability. Nat. Methods 5, 331-338 (2008).

25. Fehrentz, T., Schonberger, M. \& Trauner, D. Optochemical genetics. Angew. Chem. Int. Ed. 50, 12156-12182 (2011).

26. Grell, W. et al. Repaglinide and related hypoglycemic benzoic acid derivatives. J. Med. Chem. 41, 5219-5246 (1998).

27. Takahashi, T. et al. Antidiabetic sulfonylureas and cAMP cooperatively activate Epac2A. Sci. Signal 6, ra94 (2013).

28. Zhang, C. L. et al. The cAMP sensor Epac2 is a direct target of antidiabetic sulfonylurea drugs. Science 325, 607-610 (2009).

29. Herbst, K. J., Coltharp, C., Amzel, L. M. \& Zhang, J. Direct activation of Epac by sulfonylurea is isoform selective. Chem. Biol. 18, 243-251 (2011).

30. Hodson, D. J. et al. Lipotoxicity disrupts incretin-regulated human beta cell connectivity. J. Clin. Invest. 123, 4182-4194 (2013).

31. Rutter, G. A. \& Hodson, D. J. Minireview: intraislet regulation of insulin secretion in humans. Mol. Endocrinol. 27, 1984-1995 (2013).
32. Quesada, I., Nadal, A. \& Soria, B. Different effects of tolbutamide and diazoxide in alpha, beta-, and delta-cells within intact islets of Langerhans. Diabetes 48, 2390-2397 (1999).

33. Santos, R. M. et al. Widespread synchronous $[\mathrm{Ca} 2+] \mathrm{i}$ oscillations due to bursting electrical activity in single pancreatic islets. Pflugers Arch. 418, 417-422 (1991).

34. Head, W. S. et al. Connexin-36 gap junctions regulate in vivo first- and secondphase insulin secretion dynamics and glucose tolerance in the conscious mouse. Diabetes 61, 1700-1707 (2012).

35. Jonkers, F. C., Guiot, Y., Rahier, J. \& Henquin, J. C. Tolbutamide stimulation of pancreatic beta-cells involves both cell recruitment and increase in the individual $\mathrm{Ca}(2+)$ response. Br. J. Pharmacol. 133, 575-585 (2001).

36. Gorostiza, P. \& Isacoff, E. Y. Optical switches for remote and noninvasive control of cell signaling. Science 322, 395-399 (2008).

37. Velema, W. A., Szymanski, W. \& Feringa, B. L. Photopharmacology: beyond proof of principle. J. Am. Chem. Soc. 136, 2178-2191 (2014).

38. Stein, M. et al. Azo-propofols: photochromic potentiators of GABA(A) receptors. Angew. Chem. Int. Ed. 51, 10500-10504 (2012).

39. Tochitsky, I. et al. Optochemical control of genetically engineered neuronal nicotinic acetylcholine receptors. Nat. Chem. 4, 105-111 (2012).

40. Mourot, A. et al. Rapid optical control of nociception with an ion-channel photoswitch. Nat. Methods 9, 396-402 (2012).

41. Lemoine, D. et al. Optical control of an ion channel gate. Proc. Natl Acad. Sci. USA 110, 20813-20818 (2013).

42. Velema, W. A. et al. Optical control of antibacterial activity. Nat. Chem. 5, 924-928 (2013).

43. Broichhagen, J., Jurastow, I., Iwan, K., Kummer, W. \& Trauner, D. Optical control of acetylcholinesterase with a tacrine switch. Angew. Chem. Int. Ed. 53, 7657-7660 (2014).

44. Proks, P., Reimann, F., Green, N., Gribble, F. \& Ashcroft, F. Sulfonylurea stimulation of insulin secretion. Diabetes 51(Suppl 3): S368-S376 (2002).

45. Caro, L. N., Moreau, C. J., Estrada-Mondragon, A., Ernst, O. P. \& Vivaudou, M Engineering of an artificial light-modulated potassium channel. PLOS ONE 7, e43766 (2012).

46. Reinbothe, T. M., Safi, F., Axelsson, A. S., Mollet, I. G. \& Rosengren, A. H. Optogenetic control of insulin secretion in intact pancreatic islets with betacell-specific expression of Channelrhodopsin-2. Islets 6 (2014).

47. Ye, H., Daoud-El Baba, M., Peng, R. W. \& Fussenegger, M. A synthetic optogenetic transcription device enhances blood-glucose homeostasis in mice. Science 332, 1565-1568 (2011).

48. Butler, P. C., Dry, S. \& Elashoff, R. GLP-1-based therapy for diabetes: what you do not know can hurt you. Diabetes Care 33, 453-455 (2010).

49. Nauck, M. A. \& Friedrich, N. Do GLP-1-based therapies increase cancer risk? Diabetes Care 36(Suppl 2): S245-S252 (2013).

50. Rossger, K., Charpin-El-Hamri, G. \& Fussenegger, M. A closed-loop synthetic gene circuit for the treatment of diet-induced obesity in mice. Nat. Commun. 4 2825 (2013).

51. Grossweiner, L. I., Jones, L. R., Grossweiner, J. B. \& Rogers, B. H. G. The Science of Phototherapy: an Introduction (Springer, 2005).

52. Deisseroth, K. Optogenetics. Nat. Methods 8, 26-29 (2011).

53. Barretto, R. P. et al. Time-lapse imaging of disease progression in deep brain areas using fluorescence microendoscopy. Nat. Med. 17, 223-228 (2011).

54. Kim, T. I. et al. Injectable, cellular-scale optoelectronics with applications for wireless optogenetics. Science 340, 211-216 (2013).

55. Seino, S., Shibasaki, T. \& Minami, K. Dynamics of insulin secretion and the clinical implications for obesity and diabetes. J. Clin. Invest. 121, 2118-2125 (2011).

56. Pocai, A. et al. Hypothalamic K(ATP) channels control hepatic glucose production. Nature 434, 1026-1031 (2005)

57. Martinez, C. H. \& Dardonville, C. Rapid determination of ionization constant (pK a) by UV spectroscopy using 96-well microtiter plates. ACS Med. Chem. Lett. 4, 142-145 (2013).

58. Altomare, A. et al. SIR97: a new tool for crystal structure determination and refinement. J. Appl. Crystallogr. 32, 115-119 (1999).

59. Sheldrick, G. A short history of SHELX. Acta Crystallogr. Sect. A 64, 112-122 (2008).

60. Hodson, D. J. et al. ADCY5 couples glucose to insulin secretion in human islets Diabetes 63, 3009-3021 (2014)

\section{Acknowledgements}

J.B. was supported by a European Foundation for the Study of Diabetes (EFSD) Albert Renold Young Scientist Fellowship (94741) and Studienstiftung des deutschen Volkes PhD studentship. D.J.H. was supported by a Diabetes UK R.D. Lawrence Research Fellowship (12/0004431) and G.A.R. by Wellcome Trust Senior Investigator (WT098424AIA), MRC Programme (MR/J0003042/1), Diabetes UK Project Grant (11/0004210) and Royal Society Wolfson Research Merit Awards. S.T. was supported by a Diabetes UK Project Grant (12/0004529). D.T. was supported by an Advanced Grant from the European Research Council (268795). The work leading to this publication has 
received support from the Innovative Medicines Initiative Joint Undertaking under grant agreement no. 155005 (IMIDIA), resources of which are composed of financial contribution from the European Union's Seventh Framework Programme (FP7/20072013) and EFPIA companies' in kind contribution (G.A.R. and P.M). We are grateful to Dr Peter Mayer from LMU Munich for X-Ray crystallography and Silke DuensingKropp, Dr Georg Höfner and Prof. Dr Klaus T. Wanner from LMU Munich for assistance with [3H]-glibenclamide studies. Lastly, we thank Mr. Ryan K. Mitchell, Miss Natalie R. Johnston and Miss Maria-Rita Paiva Pessoa from Imperial College London for technical assistance, Prof. Jin Zhang from the Johns Hopkins University for kindly providing us with the plasmid for Epac2-camps, and Drs Tatsuya Kin and Doug O'Gorman from the Clinical Islet Isolation Laboratory in Edmonton for providing human islets.

\section{Author contributions}

D.T. and D.J.H. jointly supervised the research. J.B., M.S., S.T., G.A.R., D.J.H. and D.T. conceived and designed the study. J.B., M.S., S.C.C., J.A.F. and D.J.H. performed the experiments. J.B., S.C.C. and D.J.H. performed analysis. S.T. provided reagents. P.M., M.B. and A.J.M.S. isolated and provided human islets. J.B., D.J.H. and D.T. wrote the paper with input from all the authors.

\section{Additional information}

Accession codes: Crystallographic data for JB253 have been deposited in The Cambridge Crystallographic Data Centre under accession code CCDC 1014606.

Supplementary Information accompanies this paper at http://www.nature.com/ naturecommunications

Competing financial interests: The authors declare no competing financial interests.

Reprints and permission information is available online at http://npg.nature.com/ reprintsandpermissions

How to cite this article: Broichhagen, J. et al. Optical control of insulin release using a photoswitchable sulfonylurea. Nat. Commun. 5:5116 doi: 10.1038/ncomms6116 (2014).

\section{(c) (i)}

This work is licensed under a Creative Commons Attribution 4.0 International License. The images or other third party material in this article are included in the article's Creative Commons license, unless indicated otherwise in the credit line; if the material is not included under the Creative Commons license, users will need to obtain permission from the license holder to reproduce the material. To view a copy of this license, visit http://creativecommons.org/licenses/by/4.0/ 